\title{
Perceptions of Bilingual Education Model in Spain: How to Implement a Bilingual Education Model in Turkey
}

\author{
Burhan Ozfidan ${ }^{1}$, Lynn Burlbaw \\ Texas A\&M University, USA
}

\begin{abstract}
The main target of the study is to examinethe bilingual education program in the Basque Country, and identify whether or not their bilingual education can be implemented in Turkey. In thisresearch study, we used a qualitative method including data collection through an open-ended survey and interview that illustrates the issues surrounding bilingual education in the Basque region. The survey and interviewencompassed 30 participants from K-12 teachers and the scholars in the Basque Country. The participants' answers from both survey and interviewwere gathered and analyzed. The researcher coded emergent themes in the survey and interview. According to results, the Basque region over the last decade has established a bilingual education model, which offers multiple options for the linguistic study of the Basque language, and this model is still a reputable ongoing bilingual education system. Since Turkey and Spain historically and politically have many similarities, the Basque bilingual model can be implemented in Turkey as well.

Keywords: Basque Country, Bilingual education, Turkish, Basque language
\end{abstract}

\section{Introduction}

The purpose of the study is intended to identify the obstacles and opportunities involved in setting up a bilingual education system in the Basque Country and to identify the challenges and benefits associated with the daily experience of maintaining a bilingual education program. To implement a bilingual education program, the challenges and efficiencies of the bilingual education program in the Basque County may help Turkey while they are establishing their own bilingual education program. The rationale for exploring the Basque bilingual education model is to refine and explain the difficulties, possibilities, and future plans that may be carried out in the Basque region of Spain (Ozfidan \& Demir, 2014; Zalbide \& Cenoz, 2008). By surveying individuals who have been involved in the planning and execution of such a system, more may be understood about the pitfalls and opportunities to creating such a system. Due to the historical and sociopolitical aspects of the Basque approach, it may be appropriated for use in the Turkish/Kurdish context.

The significance of the study is that if more information can be learned from the Basque Country's attempts to set up bilingual education system, it may help scholars and policymakers in Turkey in gaining broader perspectives on the establishment of language education systems as they address these questions in Turkey.

\section{Literature Review}

Turkey has historically consisted of various culture (like a cultural mosaic) and language, and a central geographic location situated between Europe and Asia continent (Aydin \& Ozfidan, 2014; Akreyi, 2011). Within the context, Turkey currently providesthese different languages ad cultures' the needs. The ethnic distribution of Turkey, according to KONDA (2011), is Turkish (78.1\%), Kurdish (13.1\%), and Lazi or Turkmen $(1.5 \%)$.

In Turkey, the Kurdish people who have been fighting for their linguistic rights for a long time are the largest ethnic subgroup in Turkey (Arzamendi J \& Genesee F. 1997; May, 2001). In1923, a written law added to Turkey's constitution prohibited the Kurdish language (Kendal, 1980; May, 2001). Therefore, according to McCarus (1960), an essential issue in Turkey is to ensure that Kurdish students are able to have education in their mother tongue. The primary concerns for the Kurds are maintaining their language and culture (Ozfidan, 2014). The Turkish government has taken democratic steps to improve the Kurd's

${ }^{1}$ Correspondence author's email: b.ozfidan@tamu.edu 
rights; however, Turkey fears that accepting education in Kurdish may cause segregation between different ethnic groups such as Kurdish and Turkish (Akreyi, 2011).

When students receive education in their mother tongue, it is certain that they can express their thoughts, ideas and feelings better in their classes (Chimbutane, 2009; Etxeberria, 2006). This in turn gives them the self-confidence that they need to be successful in their courses (Polat, 2007). If students see that their mother language and culture are valued and vital, they will seek to retain their fluency in their mother language (Singh, 2010). When they become proficient readers and writers in their own language they can apply the same method to reading and writing in the target language. All students in Turkey are essentially equal when they enter the educational environment; however, students who do not speak Turkish have an unfair disadvantage in the Turkish educational system (Faltis, 2014; Skutnabb-Kangas, \& Bucak, 1994). Therefore, there is a need in Turkey to develop a Kurdish bilingual education. Treating students equally should a primary goal of the Turkish educational system (DISA, 2011). However, students who do not speak Turkish are disadvantaged in the educational system. Therefore, bilingual educational programs should be implemented and developed in Turkey and the education system should use Kurdish to increase quality. According to Ucarlar (2011), Kurdish language's assimilation into Turkish education is quite complicated and complex issue. Using school models and design aiming to be a balanced bilingual education in both Turkish and Kurdish should have an essential role in lifting the disadvantages and damages of Kurdish students. The current issues, detailed observations, and various conditions should be considered in the education system to develop a strong model to be used for children who cannot speak Turkish(Polat, 2007). For a possible bilingual education, teacher training, governmental supports, materials, curricula, and methods are important concerns in Turkey. In these concerns, one of the most important ones is teacher training (Kaya, 2015; Skutnabb-Kangas, \& Bucak, 1994; Ucarlar, 2011). Because it is a longterm process, the Turkish government first of all should open some training department at universities. Initially, some bilingual schools should be opened particularly eastern part of Turkey because majority of Kurdish people inhabit there (DISA, 2011). Bilingual educational programs' progress can be implemented from different countries' bilingual educational programs such as bilingual education models in Spain and French immersion programs in Canada.

Currently, Kurdish language came to the curriculum as an elective course in 2012. The idea came from the Ministry of National Education inclusion of the Kurdish language as a selective course in the curricula prepared by the Ministry of National Education. It started opening the Kurdish Language and Literature Departments at certain universities, such as MardinArtuklu University in Mardin. For the future, this is a big step toward a local bilingual education program in Turkey (Ozfidan, 2014).

\section{Basque Bilingual Education in Spain}

The Basque Provincesin Spain were not provided education to learn theirmother tongue until the Constitution of 1978 (Zalbide, \&Cenoz, 2008). Spain was divided into 17 regions and 2 autonomous cities with the constitution of 1978. Catalan, Galician, Occitan, and Basque languages are accepted as the official languages of their regions in the autonomous regions (Cenoz, 2012; Etxeberria, 2006). However, during the Franco regime and resistance fighters from 1939 to 1975often hid in the Basque country, the Basque language was forbiddenofficially from schooling environment. "ETA (Euskadi ta Askatasuna, in English: Basque Homeland and Freedom) one of the oldest nationalist organizations in the world,"under Franco's dictatorship, fought for the Basque Country's independence in 1959(Gardner, 2000; Sánchez-Cuenca, 2008, p.23). This nationalist group was one of the greatest obstacles for the development ofthe Basque Country to overcome (Zuazo, 1995; Ozfidan \&Ugurlu, 2015).

\section{Bilingual Education Models in Basque Country}

Until the end of the seventies each ikastola school organized its Basque-medium teaching as it saw fit and as availability of teachers and materials allowed (Gardner, 2000; Cenoz, 2012). The expansion of Basque-medium education into the public sector led to an effort to typify the BAC bilingual educational models (Gardner, \&Zalbide, 2005). The results were the three models A, B and D, which were subsequently officially sanctioned by the 1983 bilingualism decree and confirmed by the 1993 law of Basque public schooling. According to Ozfidan (2014), these modelsare summarized as follows:

- Model A: "Spanish-medium teaching with Basque as a subject."

- Model B: "Basque- and Spanish-medium teaching with both Basque and Spanish as subjects."

- Model D: "Basque-medium teaching with Spanish as a subject." 
Models A and B were originally intended for children from Spanish-speaking homes, while D was for children from Basque-speaking homes (Arzamendi, \& Genesee, 1997; Ozfidan \& Demir. 2014). Model D, however, was from the start also popular with Spanish-speaking parents. Whilst it seems that native Basque speakers on the whole attend model D classes, children from monolingual Spanish homes can be found in all three models and frequently constitute a majority in model D classes outside hinterland areas (Haddican, 2007). Table 1 below indicates the evolution of these linguistic models:

Table 1.

Distribution of the three models aged 3-14, from 1983-84 to 1998-99

\begin{tabular}{llllll}
\hline & $\mathbf{1 9 8 3 - 8 4}$ & $\mathbf{1 9 8 6 - 8 7}$ & $\mathbf{1 9 9 0 - 9 1}$ & $\mathbf{1 9 9 6 - 9 7}$ & $\mathbf{1 9 9 8 - 9 9}$ \\
\hline Model A & $72.87 \%$ & $64.11 \%$ & $50.64 \%$ & $31.54 \%$ & $26 \%$ \\
Model B & $10.54 \%$ & $15.92 \%$ & $24.91 \%$ & $27.73 \%$ & $28 \%$ \\
Model D & $16.59 \%$ & $19.97 \%$ & $24.45 \%$ & $40.71 \%$ & $45 \%$
\end{tabular}

Source: Basque Government, 1997; Gardner, 2000.

Research questions. Three questions that were explored in this study are:

- How do Basque educators compare education in the Basque Country before and after current issues of language minority schooling?

- What do Basque educators report as the strengths and weaknesses of the system?

- How could the Basque system be appropriated for use in Turkey?

\section{Key Terms}

For the purpose of this study,bilingual education is a system of education in which information is presented to students in two different languages. The goal of bilingual education is fostering academic achievement, assisting immigrant acculturation to a new society, conserving a minority group's linguistic and cultural heritage, enabling native speakers to learn a second language, and advancing national language resources (Chimbutane, 2009). People use the term bilingualism in different ways. For some people, bilingualism means an equal capability to communicate in two languages. For others, it basically means the capability to communicate in two different languages, but with better skills in one language. Indeed, it is more prevalent for bilingual people, who have been bilingual since birth, to be slightly "dominant" in one language(Chimbutane, 2009).

For the purpose of this study,monolingualismmeans a personwho does nothave access to more than one linguistic code as a means of social communication. Monolingual is said of a text, or conversation written or conducted in just one language, and of a subject in or at which a single language is either used or officially recognized(Singh, 2010).

\section{Method}

\section{Research Design}

In order to reach the data set that explained the issues surrounding bilingual education in the Basque region, we used a qualitative method including data collection through open-ended survey and interview(Creswell, 2002). In this study, 30individuals, academics and K-12 teachers, from Basque Country in Spain were voluntarily participated. To collect the data, a survey linkwas sent to a faculty member in the Basque Country. Subsequently, the faculty member for voluntary participation sent out the request through his network of organizational and professional contacts. The other part of the data was also collected through a semi-structured interview from Basque people who have lived in Reno/Nevada in the US.

The researchers met with individuals to receive some suggestions about who would complete the interview. Individuals (pro and anti bilingualism) were sought out and followed all IRB guidelines set forth by The University of Nevada, Reno (UNR). Once individuals who agreed to participate the study were identified, the researchers met with them in their offices and discussed our purpose of collecting this data. The participants were allowed to know that participation was voluntary and they might abstain at any time during the data collection process and their data would be kept confidential. The participants were also informed that their responses would not be identifiable in the completed report.

Participants were asked to answer the questions aboutthe challenges/opportunities and the process they experienced regarding the bilingual education system in the Basque Country. The open-ended survey questionnairesand interview questions were translated into English, Basque, Spanish, andthe subjects hadthe opportunity to read the question in whatever language the participants primarily spoke. Because this 
study used purposeful sampling, the results didn't generalize beyond the particular schools or country (Creswell, 2003).

\section{Data Sources}

After the survey was completed, participants submitted the survey online, and the researcher collected the survey data via Survey Monkey. The researcher used open-ended questionnaire. According to Creswell (2003), "the open-ended survey questions seek to explore the qualitative, in-depth aspects of a particular topic and issue" (p.125). Therefore, it gave participants the chance to respond in detail.

Questions were designed to ascertain information regarding the professionals' knowledge of the Basque educational system, participants' opinions of it, their experience with it (indirect and direct), their knowledge of its success, their opinion of its success, and the obstacles and opportunities involved with it. Participants were asked to discuss what they think could be done differently in setting up the bilingual education system in the Basque Country, and to give their advice to other educators considering setting up such a system.

Another data source parallel to the open-ended surveywas interview compiled while doing this study. The researcher had the opportunity to use the University of Nevada, Reno's Basque library and interviewed with participants from the Basque Country. This led to an opportunity to think deeply about the literature and survey results.

\section{Data Analysis}

The researchers developed categories for the distinct themes that were collected from both surveys and interviews, and these categories were analyzed through Cross-case theme analysis since itreassembled the data based on logical connections between categories (Creswell, 2002). Coding categories were a means of sorting the descriptive data so that the material represented patterns among the survey and interview questions.

\section{Findings}

Thestudyexaminedthe issues surroundedBasque bilingual education curriculum in Spain. The survey and interviewweregivento 30 participants, 19 females and 10 males (Table. 1). Furthermore, 20 of the participants were K-12 teachers and 10 of them were scholars (Table. 2). Participants in different age groups were from Gipuzkoa, Bizkai, Araba in Basque Country.

Table 2.

Age group of the participants

\begin{tabular}{|c|c|c|}
\hline \multicolumn{3}{|l|}{ Are you: } \\
\hline Answer Options & Response Percent & Response Count \\
\hline$\overline{\text { Male }}$ & $32.0 \%$ & 10 \\
\hline Female & $68.0 \%$ & 19 \\
\hline Answered Questions & & 29 \\
\hline Skipped Questions & & 1 \\
\hline
\end{tabular}

Table 3.

Professional position of the participants

\begin{tabular}{lcc}
\hline Within the past 5 years, what professional positions have you held in education? \\
\hline Answer Options & Response Percent & Response Count \\
K-12 Teacher & $75 \%$ & 20 \\
K-12 Administrator & $0.0 \%$ & 0 \\
K-12 Counselor & $0.0 \%$ & 0 \\
Scholars/Faculty & $25 \%$ & 10 \\
\hline
\end{tabular}

The data analysis indicated that all participants were from different part of the Basque Country. The table 3, below, indicates that 20 participants are from Gipuzkoa, 2 participants are from Araba, and 2 participants are from Bizkaia. 
Table 4.

Region of the participants

\begin{tabular}{lll}
\hline \multicolumn{2}{l}{ What region are you from in Basque Country? } & \\
\hline Answer Options & Response Percent & Response Count \\
Araba & $9.4 \%$ & 3 \\
Bizkaia & $7.3 \%$ & 4 \\
Gipuzkoa & $83.3 \%$ & 21 \\
Nafarroa & $0.0 \%$ & 0 \\
Lapurdi & $0.0 \%$ & 0 \\
Zuberoa & $0.0 \%$ & 0 \\
Answered Questions & & 28 \\
Skipped Questions & & 2 \\
\hline
\end{tabular}

The researchers gathered and reviewed the data from the survey and interview, and emergent themes in the survey were coded as follows:

Theme One: Growing Bilingualism in the Basque Country

Participants in the survey were asked to reflect their thought regarding theBasque bilingual education programin Spain. This theme's questions was answered by 25 participants $(8$ of them were scholars and 17 of them were K-12 teachers). According to one of the teacher's responses, "because the current bilingual education has three different type of bilingual education models, current bilingualism works perfect... all three are optional...if you want to learn Basque or Spanish it is up to parents or students' decision, you can learn both Spanish and Basque language or you can learn either of them." Most of the responses were parallel to this answer. Bilingual education and bilingualism have a legal position and thenumber of bilingual speakers continuesto grow in the Basque Country. According to a scholar, "Basque language's sociolinguistic condition is better than ever before... it has large societal support and more books are published in Basque than in the entire model centuries". Anotherscholaralsostated, "My own language (Basque) hasbeen spoken in areas it has never been spoken in before, for example, in technology, in universities, churches, computer software, and official zones, and so on." The overall perspective of the participants reflected that the Basque bilingualism is of enormous interest in the context of the European Union., Most of the participants highlighted that bilingual education in the Basque Country symbolizes "a dynamic, changing scenario, full of contradictions and new proposals."

\section{Theme Two: Advantages/disadvantages of bilingual models}

Under theme two, there were 23 participants, 16 K-12 teachers and 7 scholars. 17 participants completed open-ended survey questions phase and the other 6 participants completedan interview phase for the data collection.

The researchers explored the advantages/disadvantages of bilingual education system in the Basque Country. According to a scholar, "becausea student who graduated through model D systemis equally fluent in the two official languages (Basque and Spanish), this is the only modelin the Basque region that is close to a balanced bilingualism. In this model, students'competence isbeing very good in both languages." The participants affirmed thatsince the students are bilingual in both Basque and Spanishwhen they graduate from their schools, people in the Basque Country accepts the model D as a most usefulmodel in Basque bilingual education program. The Model B is also acceptable; however, according to a teacher, "because students learn some Basque, but they can't communicate fluently so they avoid using model B, it is not as good as model D." The overall perspective of the participants affirmed that the current bilingual education program in the Basque Country increases the understanding of cultural and ideological views of the local folks and encourages the students to have a better education for their future careers.

As the disadvantages of Basque bilingual models, the participantsindicated that since the model A only focused on teaching only Spanish, parents in the Basque Country did not choose model A for their children.According to one of the teacher's responses in the survey, "Basque is just another school curriculum subject, and thus, currently, model A is tending to disappear." For bilingual models, as overall aspects of the participants "there is a lack of classrooms that can accommodate students who require instructions in both languages, Spanish and Basque. Students are expected to sit together in one class 
irrespective of their age and the differences in the required level of education."Besides this, participants highlighted "the lack of teachers" in schools.Because teachers need to teach the same subject in both Basque and Spanish, they feel stressful and frustrated. Therefore, according to aparticipant,"the teachers who teach Basque and Spanish in the same subject should be provided training to spend more time to give detailed clarification to the students and communicate with them."

In the interview phase of the data collection, the participants discussed their perception of the model C. There are three models in Basque bilingual education (model A, B, D), all of which are explained in the study. However, in this bilingual system, model $\mathrm{C}$ does not exist. The researcher's curiosity prompted him to ask the participants why they skipped model C. As a matter of fact, this question was weighing on his mind from the beginning to the end of the study. He hypothesized there was a model $\mathrm{C}$ but because it was not used frequently, it disappeared. However, the participants providedthe answer: because there is no letter $\mathrm{C}$ in the Basque alphabet they skipped model C.

\section{Theme Three: Prohibition of Language and History}

Under theme three, there were 21 participants, 5 scholars and $16 \mathrm{~K}-12$ teachers. 15 participants completedan open-ended survey and the other 6 participants completed an interview for the data collection.

Under this theme, the researchers explored the creation of the current system in the Basque Country investigating their language education.According to Haddican (2007), the Ikastolaswith a special legal status were publicly and privately funded schools. These schools started operating within the Federation of Ikastolas and they, afterwards, have merged with private and state schools. They were the first schools, which were teaching in Basque, but they are not currently existing any more. One of the participants stated, "Within the Franco'sdictatorshipperiod, Basque people often hid in the Basque Country. The Basque language was forbidden in educational zones and all official places around the Basque Country." The overall perspective of the K-12 teachers affirmed that schoolsmonolingualism in Spanish were characterized and people were forced to speak only Spanishdue to the Franco's dictatorship through 1935 to 1960. A K-12 teacherstated, "In the past, only Spanish and Spanish cultures were taught in the classroom and Basque language was not allowed to be taught in anywhere in Spain. Fortunately, after Franco regime, we went from a dictatorship to a democracy, and then we had huge changes." The development of the bilingual education program, according to the scholars, is relevant to the movement for schools in "Euskara, the Ikastolas" in the Basque Country.

In the interview phase of the data, the participants affirmed that Basque people historically have almost never been unified in a single state; however, some economic and social rights have separated the Basque people from other local populations. According to the participants, the Basque Country will an independent country and segregated from Spain. One of the participants also stated that

There are noticeably Basque types of food and drink, dance, sports, song, music, dress, religious practice, social customs, work processes among others. However, many people who consider themselves Basque now live in towns, and may display few or none of the characteristics that they exhibit in the Basque Country. Many monolingual Spanish and French people consider themselves Basque on the basis of ancestry or at least residence.

The participants and researcher discussed Kurdish and Basque historical backgrounds. They sat together and discussed some historical similarities between the two countries of Spain and Turkey. As they discovered, there were many similar events in the historical backgrounds between these two countries. For instance, both nations prohibited their minority languages -- Basque in Spain and Kurdish in Turkey -- at different periods of time.

\section{Theme Four:Challenging at universities and Preserving Language and Culture}

Under theme four, there were 22 participants, $17 \mathrm{~K}-12$ teachers and 5 scholars. 17 participants completedan open-ended survey and the other 5 participants completedan interview for the data collection.

Participants in the open-ended survey phase were asked if bilingualism helps preserve cultural heritage and linguistic background in the Basque Country. All of the participants in the study reflected affirmative aspects of the Basque Bilingual education program. According to a participant, "Traditions, language, and religion are generally described in ethnic identification." Another participant also reflected that "Basque language is the cultural symbol of Basque identity, and all cultural customs and history of the Basque groups have been recorded in their language."One of the participants stated, "if someone doesn't use his/her mother language, it will be getting rusty... Therefore, to not forget a language, people should brush up on it ...if anyone's language disappeared, that mean this person's cultural heritages and identity are 
going to be disappeared..." the new generation could not inherit their history and cultural without the language. One of the participants emphasized "the right to preserve their traditional culture and own language is one of the fundamental human rights supported by international society today." According to overall perspective of the participants, "Basque language might vanish if bilingualism did not emerge in the Basque Country, as its functions as a communication tool decline with globalization and modernization."They highlighted that the disappearance of any language is predictable even though many people cannot accept this reality emotionally. They also stated

If a small group insists on preserving their own language but rejects learning other useful languages, the group's limited ability to communicate and learn will place them at a disadvantage in international and social competition, and obstruct their future development opportunities.

In the interview, according to the participants, one of the problems universities in the Basque Country face nowadays, is the limited number of staff qualified to teach through the Basque medium. The participants pointed out that there are nearly 1,800 professors, lecturers and researchers who have the qualifications to teach through the Basque language. However, this is roughly $30 \%$ of the academic staff. Therefore, there is a mismatch between the percentage of students who enroll for courses taught in Basque and the percentage of academic staff who can teach in Basque. The participant also speculated that the use of Basque as the language of instruction is more difficult at the university because the number of courses is much larger than the number staff that can teach those courses. The courses are also highly specialized.

\section{Theme Five: Relationship between language and ethnic groups}

Under theme four, there were 23 participants, 18 K-12 teachers and 5 scholars. 18 participants completed an open-ended survey and the other 5 participants completed an interview for the data collection.

Participants in the open-ended survey phase were asked to share their ideas regarding the effectiveness of the bilingualism on both Basque and Spanish ethnic groups in the Basque Country. The participants in the study highlighted a quite positive impact of bilingualism on these two ethnic groups' relationship in the Basque Country. According to a teacher in the study,

in the Basque Country, bilingualism does not affect any ethnic groups negatively... quite the reverse, I think bilingualism makes extremelyaffirmative strong relationships between different ethnic groups (Spanish and Basque) in our country. I don't believe that bilingualism in the Basque Country creates a discrimination environment.

In Spain, bilingual education system is a political issue, because they think it may cause segregation between Basque and Spanish population. One of the scholars argued, "the bilingual education system does not separate any ethnic groups such as Spanish and Basque people in Basque Country." On the contrary,all of the participants affirmed that it increase a brotherhood environment between Basque and Spanish.

During the interview with the participants, we talked about the relationship between Spanish and Basque people. According to the participants, the relationship between the Spanish and the Basque is very complicated because of the political and historical changes. The factors related to the relationship between the Spanish and the Basque are considerable: Franco's dictatorship, migration, the development of communications, the geographic locations between Basque and Spanish group, the political configuration in the Basque Country, and among others.

\section{Theme six: Current challenging}

Under theme six, 6 participants were interviewed to expose the current bilingual education program's challenges in the Basque Country. The participants stated that Basque language learners in daily life in the past were limited and not eager to learn a second language. Recently, since most people have needed to learn a second language to involve the society, the second language learners (Basque or Spanish) have been increased. Basque, Spanish, and French speakers haveincreased neighborhood among each other. One of the participants stated, "Spanish radio and television programs, daily newspapers and other reading materials are audible or visible in the living room and are often better than those available in Basque language."The participants also believed that "languages may not carry the same importance that the mother tongue carries, and may not be loved in the same way."

\section{Limitations}

There were some limitations with using survey instruments that were taken into consideration. Once leading internet-based survey research limitations on an individual's access and skills in regard to computers reduced the number of the participants in the study. Another limitation of internet-based survey 
research was involved during collecting qualitative data. The survey and interview form for this study was written and spoken in English and many of the participants did not speak or low proficiency of English; therefore, some of the questions were misunderstood and answered inaccurately.

\section{Discussion and Conclusion}

The result of the studyindicates that the use of Basque language, and the language developmentpolicy promoted and preservedin educational environment and social life. Using a minority language as in some instances that the study highlighted has had a positive influence on the language's status. This studyalso emphasizedchallenges that the Basque Country encountered while they were working on a bilingual education program. The principal challengewhen the Basque language was started to be used in higher education 30 years ago was the teaching materials availability and the language standardization. Now many publications and textbooks consisting of on-line resources are available, and have improved enormously. The findings also indicated that the Basque language has been gaining a prestigious and strength with strong institutional and social support.

The findings indicate that the language equivalencies between Basque and Spanish were increased after the bilingual education models were involved the curriculum. To besuccessful in learning of the minority language and to socialize in a more integrated way in the community, students were provided with the linguistic tools that allowed them to learn the language. The result of the data also highlighted that model D is the only approach for students to learn a second language and to be bilingual in both Basque and Spanish. However, since model A only teaches in Spanish, very few people enroll this model; therefore it needs to be reviewed, otherwise, model A might be vanished (Etxeberria, 1999).

There are some historical and political similarities in regard to Basque language in the Basque region of Spain to Kurdish language in Turkey. This study indicated how bilingual education system in the BAC benefited the Basque people and how this situation can be related to the Kurdish question in Turkey. The Basque models are examined andconsidered thathistorical and political conditions between the Basque Country and Spain wereproblematicbefore the bilingual education was started. However, after the Franco regime, the relationship between Basque and Spanish has been getting much better then before. In a 2011 study, Coskun, Derince, and Ucarlar affirmed, "The implementation of a bilingual educational policy that accepts the use of the mother tongue in education necessitates decentralization of the administrative structure" (p.127). Adjusting a bilingual education program in Turkey compared to the Basque bilingual education programmightbenefit students to identify and exhibit a more positive attitude towards school. An anticipated bilingual education program in Turkeywould would increase students' school accomplishment and their self-confidence. Moreover, this would also enhance the students' communication skills to involve the society for societal peace.

Turkey should consider developing a bilingual education program for Kurdish students. For this development, like the measures currently being employed by Basque programs, fundamental work for the implementation of other educational measures should be performed. According the needs and changing conditions, the government should develop a bilingual education program. Within this model's development, the teachers', parents', and particularly students' needs should be considered like those of citizens of the Basque Country. To develop a Turkish model for using in Kurdish bilingual education, examining the efficiency of the Basque bilingual models might provide inspirations for a possible bilingual education in Turkey.

While establishing policies for an anticipated bilingual education program in Turkey, the difficultiesand issues occurred in the Basque Country before they started their bilingual education program should be considered. Since majority of the Kurdish people inhabits in the Eastern Provinces, a bilingual education program can start locally in the eastern part of Turkey considering the needs of the students like the bilingual education program in the Basque Country. 


\section{References}

Aydin, H. \& Ozfidan, B. (2014). Perceptions on Mother Tongue (Kurdish) Based Multicultural and Bilingual Education in Turkey. Multicultural Education Review (MER) Vol.6, No. 1, pp. 51-78

Akreyi M (2011). 19th Century mentality in 21st century: Kurdish language still banned inTurkey.From $<$ http://kurdishrights.org/2011/03/12/19th-century-mentality-in-21st-century-kurdish-languagestill-banned-in-turkey/>

Arzamendi J\&Genesee F.(1997). Reflections on immersion education in the Basque country. In K.Johnson\& M. Swain (Eds.) Immersion education: International perspectives (pp. 151-166). Cambridge, UK: Cambridge University Press.

Cenoz J.(2012). Bilingual educational policy in higher education in the Basque Country.Language, Culture \& Curriculum, 25(1), 41-55.

Chimbutane, F.S.(2009). The Purpose and Value of Bilingual Education: A Critical, LinguisticEthnographic Study of Two Rural Primary Schools in Mozambique. A thesis submitted to The University of Birmingham for the degree of Doctor of Philosophy.

Creswell, J.W.(2002). Educational research: Planning, conducting, and evaluating quantitative and qualitative approaches to research. Upper Saddle River, NJ:Merrill/Pearson Education.

Creswell, J.W.(2003). Research design: Qualitative, quantitative, and mixed methodsapproach (2nd ed.). Thousand Oaks, CA: Sage Publications.

Coskun, V., Derince, M.S., \&Ucarlar, N.(2011). Scar of Tongue: Consequences of The Ban on TheUse of Mother Tongue in Education and Experiences of Kurdish Students in Turkey. Diyarbakir Institute for Political and Social Research.

Diyarbakir Institute for Political and Social Research, (DISA) (2011). DilEgitimiModelleriveÜlke Örnekleri.

Etxeberria, F.S.(2006). Attitudes Towards Language Learning in Different Linguistic Modelsof the Basque Autonomous Community. Garcia, O., Skutnabb-Kangas, T., \& Torres-Guzman, E. (Eds) Imaginingmultilingual school: Language in Education and Glocalization (pp. 111-133). England: Multilingual Matters.

Faltis, C. (2014). Toward a Race Radical Vision of Bilingual Education for Kurdish Users in Turkey: A Commentary. Journal of Ethnic and Cultural Studies, 1(1): 1-5.

Gardner, N.(2000).Basque in education in the Basque Autonomous Community. Vitoria-Gasteiz: Basque Government.From<http:/_www_.hezkuntza.ejgv.euskadi.net/r43573/eu/contenidos/informacion/d ia6/en_2027/adjuntos/Basque_in_Education_i.pdf $>$ (Retrieved October 4, 2013).

Gardner, N., \&Zalbide, M.(2005). Basque acquisition planning. International Journal of theSociology of Language 174, 55-72.

Haddican, B.(2007). Suburbanization and language change in Basque. Language insociety,(5)Hassanpour A 1992. Nationalism and language in Kurdistan, 1918-1985. San Francisco, CA: Mellen Research University Press.

Kaya, Y. (2015). The Opinions of Primary School, Turkish Language and Social Science Teachers regarding Education in the Mother Tongue (Kurdish). Journal of Ethnic and Cultural Studies, 2(2): 33-46.

Kendal, N.(1980). The Kurds under the Ottoman Empire. In G. Chaliand (Ed.), Peoplewithout a country: The Kurds and Kurdistan. London, UK: Zed Books Ltd.

KONDA. (2011). KürtMeselesi'ndeAlglveBeklentiler (Perceptions and Expectations in the Kurdish Question). İstanbul, Turkey: İletişimYayınları.

Lasagabaster, D.(2001). Bilingualism, immersion programmes and language learning inthe Basque Country. Journal Of Multilingual And Multicultural Development, 22(5), 401-25.

May, S.(2001). Language and minority rights: Ethnicity, nationalism, and the politics oflanguage. New York, NY: Longman.

McCarus, R.E.(1960). Kurdish language studies.Middle East Journal, 14(3), 325-333.

Polat, N.(2007). Socio-psychological factors in the attainment of L2 native-like accent of Kurdish origin young people learning Turkish in Turkey. Dissertation, The University of Texas at Austin.

Singh, R.(2010). Multilingualism, sociolinguistics and theories of linguistic form: someunfinished reflections. Language Sciences, 32(6), 624-637. doi:10.1016/j.langsci.2010.08.005

Skutnabb-Kangas,T., \&Bucak, S.(1994).Killing a mother tongue: How the Kurds are deprived oflinguistic human rights. In T. Skutnabb-Kangas and R. Phillipson (Ed.), Linguistic human rights: Overcoming linguistic discrimination. Berlin, Germany: Mouton de Gruyter. 
Ozfidan B. (2014). The Basque Bilingual Education System: A Model for a Kurdish Bilingual Education System in Turkey. Journal of Language Teaching and Research.Vol. 5, No. 2, pp. 382-390.

Ozfidan, B., \&Ugurlu, O. (2015). The Idea Of Race And Racial Differences.Electronic International Journal of Education, Arts, and Science, 1(1), 85-98.

Ozfidan, B. \& Demir. H. (2014). Bask Cift Dilli Egitimi ve Bunun Turkiyedeki Olasi Cift Dilli Egitim Icin Orneklendirilmesi. Asian Journal of Instruction (AJI), 2(1(ÖZEL)), 77-85.

Ucarlar, N.(2009). Betweenmajority power and minority resistance: Kurdish linguistic rightsin Turkey.Printed by Media-Tryck, Lund, Sweden: Lund University.

Zalbide, M., \&Cenoz, J.(2008). Bilingual education in the Basque Autonomous Community: Achievements and challenges. Language, Culture And Curriculum, 21(1), 5-20.

Zuazo, K.,(1995). The Basque Country and the Basque language: An overview of the externalhistory of the Basque language. I n J.I. Hualde, J.Lakarra \& R.L. Trask (eds.) Towards a History of the Basque Language (pp. 5-30). Philadelphia, Pennsylvania: John Benjamins. 